\title{
ENSINO SUPERIOR: REFLEXÕES SOBRE AVALIAÇÃO INSTITUCIONAL E RANKING
}

\author{
HIGHER EDUCATION: REFLECTIONS ON INSTITUTIONAL ASSESSMENT AND RANKING \\ EDUCACIÓN SUPERIOR: REFLEXIONES ACERCA DE LA EVALUACIÓN INSTITUCIONAL \\ Y RANKING
}

Erika Bataglia da Costa ${ }^{1}$ ${ }^{1}$ Doutoranda em Ciências da Educação pela Universidad Católica de Santa Fe (UCSF) - Santa Fe - Argentina.

Resumo: A necessidade de avaliação institucional para garantir a qualidade do ensino é algo que, no Brasil, se discute de forma mais intensa a partir da implantação da LDB e a possibilidade da formação em nível superior não somente por instituições públicas, mas também privadas. Proporcionar uma avaliação que seja voltada para o conhecimento dos desafios e superação das dificuldades das IES visando proporcionar educação de qualidade é fundamental, mas a maneira como tais avaliações são feitas e seus resultados são disseminados é objeto de debate neste artigo. A metodologia adotada é de abordagem qualitativa, com objetivo exploratório e com procedimento bibliográfico. Foram utilizados, para embasamento teórico, autores como Alemán, Barsky, Bernasconi, Martinez e Vroeijenstijn. Concluise que, apesar de necessária, a maneira como as avaliações institucionais estão sendo desenvolvidas e seus resultados amplamente difundidos pode prejudicar IES em desenvolvimento, além de não demonstrar a veracidade da qualidade que se propuseram a analisar.

Palavras-chave: Avaliação institucional; Ranking; Formação para autonomía.

Abstract: The need for institutional assessment to ensure the quality of teaching is something that, in Brazil, has been discussed more intensely since the implementation of LDB (Brazilian Educational Law) and the possibility of higher level training not only for public, but also for private institutions. Providing an assessment that is dedicated to investigating the challenges and overcoming difficulties of IES, in order to provide quality education, is fundamental, but the way in which these assessments are carried out, and their results disseminated, is the object of debate in this article. In terms of methodology, a qualitative approach is adopted, with exploratory objectives, and in terms of procedure, a literature review was used. Theoretical background was drawn from authors such as Alemán, Barsky, Bernasconi, Martinez and Vroeijenstijn. We conclude that although necessary, the way in which institutional assessments are being carried out, and their results widely disseminated, may be harmful for developing IES, and do not accurately demonstrate the true quality of teaching that they claim to analyze.

Keywords: Institutional assessment; Ranking; Autonomy training.

Resumen: La necesidad de evaluación institucional para garantizar la calidad de la enseñanza es algo que en Brasil se discute de forma más intensa a partir de la implantación de la LDB y la posibilidad de la formación a nivel superior no solo por instituciones públicas, sino también privadas. Es fundamental que se produzca una evaluación de la superación de los desafíos y de las dificultades de las IES para proporcionar educación de calidad, pero la forma en la que se realizan tales evaluaciones y cómo sus resultados son divulgados es objeto de debate en este artículo. La metodología adoptada es de abordaje cualitativo, con objetivo exploratorio y con procedimiento bibliográfico. Se utilizaron, para las bases teóricas, autores como Alemán, Barsky, Bernasconi, Martínez y Vroeijenstijn. Concluimos que, a pesar de ser necesaria, la manera como las evaluaciones institucionales están siendo 
desarrolladas y sus resultados ampliamente difundidos pueden perjudicar IES en desarrollo, además de no demostrar la veracidad de la calidad que se propusieron a analizar.

Palabras clave: Evaluación institucional; Ranking; Formación de la autonomía.

\section{INTRODUÇÃO}

A discussão sobre a avaliação de instituições de ensino superior e a divulgação de seus resultados são temas que vêm gerando muitas repercussões nos últimos anos. A educação superior está estruturada com base no contexto neoliberal com estilo muito próprio de gestão de negócios, que geram grande impacto na forma como as Instituições de Ensino Superior (IES) são avaliadas e como essas avaliações aparecem para a sociedade, baseando-se muitas vezes em agências globais, como o Banco Mundial, e diminuindo a autonomia, a diversidade e a independência acadêmicas. Muitas vezes são criadas políticas de avaliação dentro do padrão neoliberal, que diz prezar a qualidade, mas que pode ter conceitos sobre o que é qualidade muito diferentes daqueles das instituições dedicadas à educação.

$\mathrm{Na}$ área da educação, uma boa avaliação deve ser desenvolvida levando-se em conta seu objetivo maior, que é a melhoria da qualidade na educação. A avaliação deve ser embasada em critérios e normas para poder cumprir com esse objetivo e não ser apenas uma obrigação burocrática para as instituições de ensino superior, tornando-as mais preocupadas com as sanções e as vantagens do que com a melhoria mesma da qualidade.

Apesar das avaliações externas proporem sugestões de melhorias, sabe-se que os cursos que não cumprem com o que foi solicitado podem ter diminuído o seu aporte financeiro ou mesmo serem fechados. Falar-se-á mais sobre o assunto na questão número 5 , mas é importante ressaltar aqui a importância e o papel da avaliação no ensino superior para garantir que os objetivos das avaliações, internas ou externas, sejam a melhoria da qualidade na educação antes de qualquer outra coisa.

Neste texto, utilizou-se a bibliografia com Alemán; Barsky; Bernasconi; Martinez; Vroeijenstijn. Será feita uma breve explanação a partir dos autores com comentários pessoais, partindo da experiência como gestora do ensino superior nos últimos 5 anos em uma faculdade privada no Brasil. Far-se-á uma apresentação dos rankings, suas vantagens e debilidades e alternativas adequadas, além da apresentação da avaliação como alternativa para garantir ao processo educacional que atinja seu objetivo maior, que é a melhoria da sociedade.

\section{Os Rankings na Educação Superior}

O ranking na área da educação tem sua origem nos rankings desportivos, com tabelas de classificação baseadas em pontos obtidos a partir de regras bastante claras, o que reflete a qualidade dos times, das equipes ou das pessoas envolvidas. Mas avaliar equipes de esporte não é a mesma coisa que avaliar a qualidade de uma instituição de ensino superior, já que as regras são menos claras e evidentes que as de um torneio ou campeonato. 
De acordo com Barsky (2012), a origem dos modernos sistemas de avaliação universitária está associada à expansão universitária norte-americana. As IES começaram a divulgar sua produção em revistas de referência que eram facilmente sistematizadas e comparáveis, com indicadores diretos, como os índices de impacto. Essa possibilidade deslocou a atenção dos livros, até então referência máxima de qualidade. Um passo posterior que começou nos EUA e logo se espalhou foi passar de avaliação de programas e instituições ou de artigos científicos por parte de pares acadêmicos, para as comparações interinstitucionais ou rankings.

\section{Possíveis QUaLIDADES do RANKING}

Não há como negar a existência dos rankings e o seu papel no mundo neoliberal. Muitos são os que argumentam em seu favor acreditando ser uma maneira ideal de verificação da qualidade de ensino. Serão vistos em seguida os principais argumentos deste grupo.

Existem algumas razões para a existência dos rankings, como o crescente interesse por igualdade de condições da educação superior em oposição à formação das elites no âmbito da massificação da educação superior, as demandas públicas por transparências e definição de cotas, a própria obsessão no contexto neoliberal de comparação e até mesmo a preocupação com a qualidade (será visto sobre a questão da qualidade posteriormente).

De acordo com Alemán (2011), de maneira geral os rankings podem interessar a todos os atores envolvidos na educação superior. Em relação aos estudantes, estar em uma universidade bem colocada nos rankings pode ser um retorno de investimento certo, garantindo boas vagas no mercado de trabalho. Em relação aos empregadores, eles podem direcionar o recrutamento para essas mesmas universidades, dando prioridade para seus egressos. Para os governos, o ranking, segundo sua própria perspectiva do que é qualidade, pode garantir a qualidade do ensino por meio da medição do desempenho tanto entre as IES da própria região como do mundo todo, podendo, inclusive, conquistar mais recursos internacionais para as IES bem avaliadas. Em relação aos professores, geralmente estar em uma IES bem avaliada significa mais reconhecimento e valorização pelo seu desempenho, além de maiores aportes financeiros para pesquisas. Para as instituições, comparar-se com as demais instituições em sua área pode fazer com que elas tenham a percepção das melhorias que devem implementar para poder se igualar no ranking, o que indiretamente pode levar à melhoria na qualidade da educação.

O modelo de universidade ideal adotado pelos rankings é um modelo implícito de qualidade na educação em vigência no mercado. Desta maneira, pode-se dizer que o ranking, apesar das críticas que se façam a ele, coloca em destaque as universidades com mais qualidade (mesmo que se possa questionar o conceito de qualidade referido), já que ninguém questiona, e até toma como óbvia, a qualidade em instituições como Harvard, Cambridge, Stanford e Oxford, por exemplo, que sempre aparecem no topo dos rankings.

Estar bem avaliado no ranking oferece às universidades em questão uma ampla divulgação de marketing no mundo todo, o que faz com que aqueles alunos mais brilhantes em sua área procurem tais instituições para estudar, alimentando o processo de qualidade. Outro aspecto 
importante em qualquer avaliação é que é necessária certa simplificação das informações para permitir uma análise comparativa, e todas as pessoas que buscam as informações em rankings devem ter em conta que os seus indicadores são baseados em dados, mesmo que subjetivos, demonstrando a realidade da qualidade da educação de forma muito aproximada.

Segundo alguns defensores dos rankings, a crítica feita aos mesmos advém de instituições que não conseguem alcançar os níveis que os rankings avaliam, rechaçando-os, portanto, baseando-se em sua culpabilidade e impotência para desenvolver-se a ponto de estar entre as melhores. Tal comparação remete à moral do ressentido de Nietzsche (1998), em que o fraco se ressente contra o forte por não ter sua força e o critica chamando-o de mau, transformando assim sua fraqueza em força (por renúncia, bondade, paciência e resignação).

\section{Os Rankings Times e Shangai}

Entre os anos de 1999 e 2001, um grupo da Universidade de Shanghai elaborou um projeto para comparar as principais universidades chinesas com universidades dos Estados Unidos, com o objetivo de reduzir a diferença entre estas universidades. Basicamente ele surge pelo interesse de o governo chinês desenvolver algumas de suas universidades e incluílas entre as primeiras do mundo. Como consequência deste projeto surgiu a ARWU (Academic Ranking of World Universities). Seu ranking foi publicado pela primeira vez em 2003. Este ranking não leva em conta todas as universidades do mundo, ele analisa 1.000 das 17.000 (números de 2012) e somente 500 são reconhecidas em seu ranking. Leva em conta somente as IES mais importantes em investigação com resultados importantes publicados nas melhores revistas de cada área, tendo entre seus critérios a quantidade de prêmios Nobel de seus professores e egressos, entre outros.

Como os principais parâmetros têm a ver com investigação, a qualidade do corpo docente, por exemplo, se mede de forma indireta, o que pode ser bastante discutível.

Em relação à Times Higher Education World University Ranking, esse ranking foi publicado pela primeira vez em 2004 e em 2010 adotou nova metodologia. Ela publica o resultado geral das IES analisadas e ainda elabora uma lista das principais por continente e por matéria (engenharia e tecnologia; arte e humanidades; saúde; ciências da vida; física e ciências sociais). Ela utiliza 13 indicadores de rendimento que incluem todas as atividades da universidade, os quais são divididos em cinco categorias: docência, investigação, referências, ingressos empresariais e aspectos internacionais. Leva em conta também a opinião dos acadêmicos e dos empregadores. Segundo Barsky (2012), a Times, tentando fugir da mera avaliação centrada nas investigações, delimitou um percentual decisivo de pontuação a avaliações subjetivas baseadas nas opiniões dos acadêmicos e dos empregadores. O problema é que os acadêmicos não poderiam ter uma visão razoável das universidades, das quais só conhecem pequenas partes associadas às disciplinas que dão ou são repetidores de opiniões com base em propagandas e outros mecanismos que elas mesmas realizam. Processo parecido acontece com os empregadores, que tampouco têm uma visão integral do mundo dos egressos, suas capacidades adquiridas 
e suas inserções laborais. Por isso a metodologia aplicada nesses rankings são um segredo porque, ao serem reveladas, advertiriam a fragilidade da informação.

Como se viu, o Shangai e a Times não demonstram resultados de todos os países, mas apenas daqueles específicos segundo o objetivo de cada metodologia, o que não quer dizer que os demais países não possuam avaliação de suas instituições, elas existem de várias maneiras, como as avaliações institucionais e autoavaliações, que será visto posteriormente.

\section{DeBILIDADES DO RANKING}

Muitas são as críticas feitas aos rankings. Segundo Alemán (2011), entre as principais debilidades, pode-se destacar os problemas de legitimidade quanto à metodologia escolhida, como a validez dos indicadores como fonte de aproximações da realidade; a ausência de credibilidade das fontes de informação utilizadas; a possibilidade de interpretação ou manipulação de dados; a falta de acordo sobre o que é de fato qualidade; os desvios constantes na metodologia, que implicam dificuldade de comparação de anos diferentes; a discriminação negativa de alguns rankings em relação à docência e certos cursos na área de humanidades; o fato de não levar em conta a diferença de perfil das IES; a quase ausência daquelas que não publicam em inglês; o desempenho atual ou o potencial futuro encoberto pelo mau desempenho do passado e as IES em países em desenvolvimento. Além disso, os rankings, segundo o autor, favorecem a concentração de recursos e sistemas nacionais altamente estratificados e acabam com a meritocracia institucional, pois dão maior peso à reputação e não reconhecem o esforço ou a contribuição de novas IES.

Enquanto as comparações eram dentro do mesmo país e com as mesmas disciplinas, as comparações eram controláveis, mesmo quando se incorporam critérios subjetivos, como pesquisas de opinião. Entre os acadêmicos se supunha que os níveis de conhecimento direto poderiam mitigar a dificuldade de registrar adequadamente as fortalezas e as debilidades das IES. O problema começa a ficar maior quando se iniciam as comparações externas.

Mostrou-se a debilidade dos indicadores que medem a qualidade do ensino. $\mathrm{O}$ que acontece é que é impossível para essas consultorias fazerem uma revisão pormenorizada de todas as informações de cada universidade e por isso aplicam indicadores simples. Por outro lado, o peso dado a cada indicador é totalmente arbitrário e ignoram o eixo central de cada projeto institucional universitário, que não pode definir-se em termos internacionais, porque depende da especificidade de cada instituição universitária, e quanto maior a instituição, mais difícil é fazer um juízo de valor geral, pois disciplinas e cursos não podem ser agregados em uma nota média.

De acordo com Barsky (2012), a supervalorização dos rankings pode levar as instituições a centrarem suas necessidades de melhorias especificamente nos aspectos que cada ranking mais valora, para tentar melhorar sua posição, deixando de lado outros aspectos muito importantes, que podem levar à melhoria da qualidade. Por esse, entre outros motivos, é que se acredita que, nas políticas para a educação superior, não se devem levar em conta somente os rankings. 


\section{Os Rankings e a América Latina}

De acordo com Bernasconi (2013), a edição de 2012 da Times Higher Educacion World Universitie Ranking não colocou nenhuma IES latino-americana entre as 100 melhores, e apenas 4 ficaram entre as 400 melhores. $O$ ranking de Shangai de 2012 também não tratou as IES latino-americanas melhores, colocou 1 entre as 150 primeiras e 10 entre as 500 primeiras, algo estranho, já que o Brasil é a $6^{a}$ economia do mundo e o México, a $14^{a}$, enquanto IES com menor desenvolvimento, como Israel e Holanda, aparecem no ranking chinês.

As IES líderes da América Latina perceberam que havia alguma coisa errada no ranking, afirmando que eles eram tendenciosos e injustos e que as IES da América Latina eram essencialmente diferentes do conceito implícito dos rankings, já que, segundo os líderes, as instituições da América Latina, conforme elas mesmas sugerem em suas missões, possuem forte missão social.

Um grupo de líderes das instituições se encontrou em 2012, a convite da UNESCO, no México para discutir o ranking e o que fazer sobre isso. Concluíram que a forma como os rankings medem é inválido tanto no seu índice composto como a todas as variáveis propostas para medir. Outra conclusão é que os rankings são naturalmente impróprios para reconhecer as IES latino-americanas, já que os padrões utilizados são das universidades anglo-saxônicas. Os reitores também perceberam que esse viés que favorece o modelo anglo-saxão é reforçado pelo uso do ISI - Tompson routers and SCOPUS, que recolhe o material principalmente publicado na Inglaterra e nas áreas de ciências da saúde e da engenharia.

Obviamente a América Latina não é a única região que reclama dos rankings, a Ásia tem motivos de sobra para também reclamar, no entanto, IES da Korea, Singapura, Taiwan e China estão mostrando grande progresso no ranking. Por terem poucas revistas próprias de qualidade, esses países, assim como Israel e Holanda, escrevem em inglês, o que os ajuda a aparecer nos rankings.

Apesar das reclamações, que parecem válidas, as instituições da América Latina poderiam ter mais representatividade nos rankings, especialmente a partir da década de 1990, quando países como Chile, Brasil e México tiveram aportes financeiros internacionais e aumentaram sua pesquisa, mas os resultados ainda não fizeram grande diferença internacionalmente.

\section{Alternativas aos Rankings Tradicionais}

Alemán (2011) ressalta que, em função desses problemas, alguns responsáveis pelos rankings no mundo começaram a discutir novas metodologias, como Berlin Principles of Ranking of Higher Educacion Institucions. Entre seus propósitos e metas estão a adoção dos rankings não como mecanismos exclusivos, nem o mais importante, para orientar a gestão acadêmica, a clareza sobre seus propósitos e grupos objetivos, o reconhecimento à diversidade de instituições, a contribuição para a clareza e transparência das informações utilizadas e suas fontes e levar em conta os contextos sociais, culturais, econômicos dos diversos sistemas 
educativos. Em relação ao desenho e à ponderação dos indicadores, usar uma metodologia mais transparente, escolhendo os indicadores pela sua relevância e validez e não os alterando constantemente. O novo modelo de ranking também deve usar padrões éticos no recolhimento das informações com métodos comprovados cientificamente, usando dados verificáveis e adotando medidas de assegurar a qualidade deste trabalho para garantir a credibilidade do ranking. Além disso, ao apresentar os resultados, devem deixar claros quais os fatores levados em conta e como foram feitas as pesquisas para não gerar dúvida no entendimento das informações.

Além de Berlin, o Mapa de la Educación Superior en América Latina y el Caribe (MESALC), coordenado pela UNESCO, também propõe mudanças nos rankings, como o reconhecimento da diversidade das instituições antes mesmo de sua qualidade, levando em conta várias dimensões como a docência, a investigação, a transferência de conhecimento, a orientação internacional e o compromisso regional. Também não deve consolidar as dimensões em um só resultado, permitindo a análise por dimensão ou disciplina e o reconhecimento das especificidades regionais.

Algumas alternativas aos rankings tradicionais apareceram, como o U-MULTIRANK, da União Europeia, que tem mais de 850 IES, é multidimensional e dirigida ao usuário que pode selecionar por áreas e comparar; o INFOACES, da América Latina, que tem 33 sócios de 23 países, que é similar ao U-M, mas com informações mais básicas e limitadas; o EXECUM, do México, somente com universidades mexicanas, o qual possui informações comparadas entre ensino, investigação, financiamento e de padrões de qualidade.

O grande desafio para a utilização dos rankings é melhorar a quantidade e a qualidade das informações que ele capta e como essas informações geram indicadores de qualidade adequados. Além disso, devem também garantir maior clareza e transparência na divulgação de tais resultados.

Se tantos são os problemas na metodologia adotada pelos rankings, por que eles possuem tanto crédito no mercado? Como se viu, os rankings são o reflexo do mundo neoliberal da livre concorrência (algumas vezes sem medida) e são utilizados como forte ferramenta de divulgação, como se viu, mas somente se beneficiam deles as grandes instituições ou mesmo corporações de ensino. Além disso, ao não fazer uso das avaliações institucionais para o desenho e desenvolvimento de políticas para o setor nem para a distribuição de recursos ou para gestar o sistema universitário, a avaliação institucional não teve seu valor reconhecido pela sociedade, e este vazio na legitimidade por parte do Estado deu espaço para o crescimento da difusão midiática dos rankings, segundo Barsky.

Segundo Takata (2015), o "sucesso" se dá porque os rankings simplificam os resultados e comparam as instituições, e num mundo competitivo isso facilita a divulgação, a compreensão e tem apelo de público e de mídia. Além disso, os rankings ganharam popularidade por fornecerem um modo simples, rápido e fácil de medir e comparar a performance e a 'qualidade' do ensino superior em nível internacional, o que é especialmente importante para estudantes, empregadores e outros que têm pouco ou nenhum conhecimento local sobre as diferentes instituições e qualidade da experiência educacional. 
Essa proeminência e influência dos rankings tem motivado uma análise crítica por parte de acadêmicos e especialistas em políticas universitárias. Em 2011, a Unesco realizou, em sua sede em Paris, em parceria com o Banco Mundial e a Organização para a Cooperação e Desenvolvimento Econômico (OCDE), fórum global 'Fórum on Rankings and Accountability in Higher Education: Uses and Misuses". Segundo o fórum, os rankings foram bem-sucedidos em pontos como colocar em consideração a qualidade em um quadro internacional comparativo maior, tornar o mundo da educação superior mais competitivo e multipolar e chamar a atenção para a importância de boas informações comparativas sobre qualidade: performance, produtividade, valor do investimento e retorno do investimento público. Por outro lado, concluiu-se que, em um universo de mais de 16 mil IES, o foco é em menos de 1\% das instituições (as top 100 das classificações). O fórum também apontou que os rankings não revelam nada sobre como a educação superior dos países funciona e que encorajam as nações a focarem-se desproporcionalmente nas instituições de elite - de forma que a ênfase desproporcional na pesquisa possa prejudicar o ensino e a aprendizagem.

\section{Avaliação da Qualidade X Rankings}

Dissertar sobre a qualidade da avaliação de instituições de ensino superior não é algo simples, mas é muito importante. Tal tema será debatido mais profundamente na questão 5 destas reflexões, mas se fará aqui um breve resumo dos motivos pelos quais a avaliação da qualidade deve ser usada como forma mais adequada que os rankings para demonstrar a qualidade de uma IES.

É preciso ressaltar que o objetivo principal da avaliação é melhorar a qualidade da educação e, consequentemente, a vida da sociedade; enquanto o dos rankings é classificar e difundir essa classificação com fins de marketing, prioritariamente. Além disso, mesmo que as avaliações não sejam tão simples de divulgar para a opinião pública, isso não é insuperável e pode ser feito de várias maneiras, inclusive de forma indireta a partir da qualidade do egresso que atuará no mercado.

A avaliação é feita de maneira mais ampla e pode captar melhor as particularidades de cada curso, de cada faculdade, ao longo do tempo, pois a qualidade não é estática nem pode ser demonstrada com critérios simplificados e/ou objetivos como os rankings. A metodologia aplicada nas avaliações da qualidade são apropriadas cientificamente, iniciando pela autoavaliação e seguida pela avaliação externa feita por pares, em muitos casos, e mesmo quando são feitas entrevistas ou questionários mais subjetivos, ainda assim é mais fácil de perceber as contradições quando se faz uma autoavaliação, pois ela é feita normalmente por atores dentro da instituição com o olhar voltado para perceber as qualidades e as debilidades da IES, e normalmente são pessoas preparadas para tal ação.

Algumas pessoas que defendem a avaliação em vez do ranking o fazem levando em conta que os rankings são voltados para interesses comerciais e de mercado, enquanto as autoavaliações não são. Neste caso, discorda-se; mesmo as faculdades públicas também se voltam para o mercado, pois em muitos casos é ele quem ajuda a definir as políticas públicas 
de financiamento e aportes financeiros para pesquisa, entre outros, portanto não se pode falar que os rankings são voltados para o mercado e as universidades não. Obviamente que as universidades se preocupam menos com isso, mas não estão totalmente à margem, como se debateu na questão número 1.

Como em quase todos os aspectos no mundo neoliberal, o modelo de universidade implícito nos rankings é generalizado, seguindo um padrão de mercado, mas não é o único possível e não tem por que generalizar um modelo diante de tantas diferenças contextuais.

Ao contrário dos rankings, que se baseiam em modelos predefinidos, como nos esportes, que possui regras claras e cujos todos os envolvidos, a priori, possuem a mesma possibilidade de vencer, nas universidades os contextos são muito diversos e não é justo comparar universidades grandes, já estabelecidas, de grande reconhecimento do público, com IES mais novas e em processo de desenvolvimento. Ao fazer um ranking sem levar isso em conta, corre-se o risco de rotular algumas instituições que até poderiam se desenvolver, mas perdem essa oportunidade, pois os números do ranking aparecem quase imediatamente no mercado e muitos alunos que poderiam procurar essas IES, e inclusive auxiliá-las no processo de desenvolvimento, simplesmente se negam a isso e procuram outras instituições.

Avaliar depende do objetivo que se queira dar prioridade, e isso é levado em conta na autoavaliação e na avaliação externa, mas não nos rankings.

“Em minha experiência como gestora da educação superior, eu estive em várias funções como psicopedagoga, ouvidora, vice-diretora e diretora acadêmica, além de presidente da Comissão Permanente de Avaliação (CPA), órgão exigido pelo MEC dentro de cada instituição de ensino superior e responsável pela autoavaliação da mesma. Nestas funções, por várias vezes, percebi que os objetivos dos mantenedores eram voltados para o lucro e não para a qualidade em si, mas com a cobrança cada vez mais direta e objetiva do órgão do Ministério da Educação para tais ações, os processos deveriam seguir de forma mais simples e direta. Apesar disso, mesmo a CPA apontando as melhorias necessárias a partir de sua autoavaliação, muitas vezes os mantenedores não se sensibilizavam e solicitavam que pequenas mudanças fossem feitas nos relatórios, para que não houvesse impacto negativo quando a avaliação externa fosse feita. Além de extremamente complicado, pois isso implicava alterar números e tentativa de alterar percepções (especialmente de professores e estudantes, fortemente implicados no processo), tal atitude era extremamente antiética, o que me levou a questionar diversas vezes e ser ameaçada caso não agisse da forma solicitada. Depois de mais de 5 anos à frente de todos esses processos, lutando pela melhoria da qualidade nas instituições a que me refiro, mesmo conseguindo muitas vezes melhorar as condições gerais de ensino e aprendizagem e com isso melhorando a qualidade da IES, percebi que as mudanças não eram feitas por uma cultura de avaliação que baseia a gestão, mas por medo de sanções advindas do poder público e suas avaliações externas.

Também acredito que a melhor maneira de se fazer propaganda de um bom curso é a sua qualidade, atestada pelos alunos, apoiada pelos professores, parte fundamental do processo, mas que a cada dia, especialmente nas instituições privadas, tem menos reconhecimento e subsídios para um bom trabalho".* 
Barsky (2012) conclui que fica claro que tanto a avaliação externa quanto a autoavaliação devem ocorrer segundo o marco de objetivos de cada instituição, tornando inadequado o ranking destas instituições, já que é uma avaliação institucional abstrata com indicadores genéricos que prescindem dos objetivos definidos pelas IES. A riqueza do princípio de autoavaliação baseada na autonomia das IES contrasta com a pobreza informativa em que se baseiam as metodologias dos rankings. A autoavaliação deve conter informação quantitativa e qualitativa para permitir um julgamento adequado da IES, isto não implica o acúmulo abusivo de estatísticas que podem prejudicar a análise.

É importante analisar a IES em seu contexto, como uma unidade de análise, e não em comparação com todas as outras. Talvez, apenas talvez, poderia se comparar várias instituições, mas apenas como foi dito antes, comparando-se aquelas com características e contextos semelhantes, mas não é assim que os rankings funcionam, infelizmente.

"Concluindo, em meu ponto de vista, o objetivo da avaliação é melhorar a qualidade, enquanto o dos rankings é somente classificar e difundir essa classificação com fins de marketing. Há quem diga que os rankings podem melhorar a qualidade do ensino porque as faculdades, ao se verem embaixo no ranking, ou ausente deles, tentarão fazer de tudo para melhorar a qualidade para poder estar no ranking. Mesmo que isso aconteça, não é pelo motivo ideal da educação, que é melhorar a vida das pessoas e da sociedade, não para aparecer na mídia. Claro que não se deve negar o valor indireto da melhoria da qualidade, mas tal melhoria deveria prescindir da necessidade de rankings para ocorrer."*

As universidades, por meio de seus acadêmicos e da web, deveriam sofisticar a informação sobre a oferta universitária, os recursos humanos e outros disponíveis, a produção acadêmica e todas as outras informações úteis para os usuários. Assim como em 1995 se iniciou uma cultura de avaliação na Argentina, período similar no Brasil, hoje se deve propor também a cultura da informação para enfrentar adequadamente a demanda por conhecer a qualidade das IES, aspecto sobre o qual se apoiam os rankings.

Por outro lado, objetar a pobreza conceitual dos rankings não é dar pouca importância à avaliação nem ignorar os mecanismos nacionais e internacionais construídos para divulgar a produção científica, mas respeitar as particularidades, como se viu. Os rankings, em sua parcialização e ordenamento arbitrário de pobreza conceitual, só distraem as universidades de seus objetivos mais transcendentes e adequados aos seus objetivos máximos.

Assim, finaliza-se com um trecho de Vroeijenstijn, (1995, p. 24), que se crê ser bastante apropriado:

Los rankings son inapropiados porque sumar la evaluación de los aspectos distintivos no tiene sentido; la evaluación detallada perderá su significado. Si los rankings se vinculan a la EEC, será una amenaza para el mejoramiento, porque las facultades sólo mostrarán sus fortalezas y no sus debilidades. Lo mismo se aplica a los vínculos directos con el financiamiento.

Pode-se concluir que a avaliação das IES é necessária, mas as formas como elas estão sendo avaliadas e como seus resultados estão sendo disseminados não auxiliam, ao contrário, prejudicam o desenvolvimento de suas potencialidades. 
ALEMÁN, Y. O. P. Algunas consideraciones críticas acerca de los rankings universitarios. Pontificia Universidad Javeriana. Reunión de la Red de Observatorios de Buenas Prácticas de Dirección Estratégica Universitaria en Latinoamérica y Europa - TELESCOPI, Barranquilla, 2011.

BARSKY, O. Acerca de los rankings internacionales de las universidades y su repercusión en argentina. In: Revista Debate Universitario, vol.1, n-1-diciembre de 2012 pp. 35-83. Buenos Aires, CAEE-UAI, 2012.

BERNASCONI, A. Are global rankings unfair to latin american universities? In: International Higher Education, number 72, p. 12-13, 2013.

MARTINEZ, E. S. Sistemas comparados de Evaluación y Acreditación Universitaria. $10^{\circ}$ COHORTE, Doctorado en Educación. Universidad Católica de Santa Fé, 2016.

NIETZSCHE, F. Genealogia da Moral. São Paulo: Companhia das Letras, 1998.

TAKATA, R. Rankings universitários internacionais: polêmica sob medida. 2016. Disponível em http:// www.oei.es/divulgacioncientifica/?Rankings-universitarios. Acesso em: 23 set. 2016.

VROEIJENSTIJN, A. I. Improvement and Accountability: Navigation between Scylla and Caribdis. London: Jessica Kingsley, 1995.

* Relato da autora em $1^{a}$ pessoa do singular.

Artigo recebido em: 14/08/2017

Aprovado em: $21 / 09 / 2017$

\section{CONTATO PARA CORRESPONDÊNCIA:}

Erika Bataglia da Costa. E-mail: erikabataglia@gmail.com 